\title{
X-ray, IR and SEM studies on some Li-Cd ferrites
}

\author{
Sudhir Kulkarni \\ Doodhsakhar Mahavidyalaya, Bidri \\ Email:-ksudhirn@gmail.com
}

\begin{abstract}
:
Lithium-Cadmium ferrites with general formula $\mathrm{Li}_{0.5-x / 2} \mathrm{Fe}_{2.5-x / 2} \mathrm{Cd}_{x} \mathrm{O}_{4}$ (with $x=$ $0,0.1,0.2 \ldots ., 0.7)$ were prepared by standard ceramic method. $X$-ray diffraction studies confirms single phase formation and lattice parameters were calculated. The crystal structure is cubic and lattice parameter increases with increasing Cd content. The infrared absorption (IR) spectra of all the samples were recorded in the range 200-800 $\mathrm{cm}^{-1}$ at room temperature in the $\mathrm{KBr}$ medium. Lithium ferrite shows four principal bands and some shoulders have been observed. The force constants $K_{t}$ and $K_{o}$ were calculated using Waldron's analysis. Scanning electron microscopy studies shows increase in grain size up to $x=0.1$ and then the grain size decreases with increase in cadmium content.
\end{abstract}

Keywords: Ceramic oxides, Ferrites, Lithium ferrites

\section{Introduction}

Ferrites are interesting and technological important materials that have been extensively studied and used for decades [1]. The use of ferrites has very well been established in many branches of telecommunications and electronics engineering embracing a very wide diversity of composition, properties and applications [2]. Hoffman reported that Lithium (Li) ferrite is magnetic with a spinel crystal structure [3]. Li ferrite possesses high curie temperature of about $650{ }^{\circ} \mathrm{C}$, high electrical resistivity [4], a square loop hysteresis [5]. Substitutions in Li ferrites makes materials suitable for the requirement of microwave devices [6].

\section{Preparation and Characterization}

The standard ceramic method was used for the ferrite samples with general formula $\mathrm{Li}_{0.5-\mathrm{x} / 2} \mathrm{Fe}_{2.5-\mathrm{x} / 2} \mathrm{Cd}_{\mathrm{x}} \mathrm{O}_{4}$ where $\mathrm{x}=0,0.1,0.2,0.3,0.4,0.5,0.6$ and 0.7 using high purity AR grade $\mathrm{Li}_{2} \mathrm{CO}_{3}, \mathrm{CdO}$ and $\mathrm{Fe}_{2} \mathrm{O}_{3}$. These powders were weighed in the required mole proportions on a semimicro balance having least count of $0.001 \mathrm{mg}$ and were mixed thoroughly in an agate mortar in acetone medium. This powder was presintered at $700{ }^{\circ} \mathrm{c}$ for 10 hours in a glow bar furnace in air medium. Then the furnace was cooled slowly. The presintered powder was then ground in an agate mortar in acetone medium. The fine powder of the resultant ferrites was obtained by sieving them through a 100-micron mesh. The mixture was then compressed in the form of pellets by using a die of $1 \mathrm{~cm}$. diameter and by applying a pressure of about 7 to 8 tonnes per square inch for 2 minutes. To reduce the lithium loss the samples were fired at 950 ${ }^{0} \mathrm{c}$ for 20 hours in air medium. The samples were furnace cooled.

For x-ray diffraction and IR absorption studies, the pellets were again grounded and sieved powder was used.

\section{X-ray diffraction studies}

In our case diffraction patterns were recorded by using Philips PW-1710 diffractometer with $\mathrm{CuK} \alpha$ radiation with wavelength $\lambda=1.5418 \mathrm{~A}^{0}$. All the samples were scanned within the range $2 \varnothing$ between $15^{\circ}$ to $85^{\circ}$. The diffractograms were indexed in the light of the crystal 
structure of a natural spinel $\mathrm{MgAl}_{2} \mathrm{O}_{4}$ by taking prominent line corresponding to (311) plane. The diffraction pattern of the sample with $\mathrm{x}=0.1$ is shown in figure 1 . The Table 1 shows values of the lattice parameter for different values of ' $x$ '. All the sample shows cubic spinel structure. The observed and calculated ' $d$ ' values are in good agreement for all indexed planes. For Li- ferrite the value of lattice parameter has been confirmed to be $8.33 \mathrm{~A}^{0}$ by many workers $[7,8]$. Our value of lattice parameter viz. $\mathrm{a}=8.324 \mathrm{~A}^{\mathrm{o}}$ in case of $\mathrm{Li}$ - ferrite agrees well with these reported values. Figure 2 shows the variation of the lattice constant with cadmium content in the sample. The lattice parameter increases linearly with the increasing $\mathrm{Cd}$ content obeying the Vegard's law. This increase in lattice parameter is explained on the basis of cation distribution and size difference of component ions.

The cation distribution of $\mathrm{Li}$ ferrite having inverse spinel structure is given by

$$
\left(\mathrm{Fe}^{3+}\right)_{\text {A }}\left[\mathrm{Li}_{0.5}{ }^{1+} \mathrm{Fe}_{1.5^{3+}}\right]_{\mathrm{B}} \mathrm{O}_{4}{ }^{2-}
$$

West and Blankenship have shown that when a nonmagnetic ion like $\mathrm{Zn}^{2+}$ is substituted in Li-ferrite, it prefers A-site transferring $\mathrm{Fe}^{3+}$ ions to octahedral site[9]. Hence the cation distribution in our case, which is $\mathrm{Cd}$ substituted Li-ferrite can be written as

$$
\left(\mathrm{Cd}_{\mathrm{x}}{ }^{2+} \mathrm{Fe}_{1-\mathrm{x}}{ }^{3+}\right) \text { A }\left[\mathrm{Li}_{0.5}{ }^{1+} \mathrm{Fe}_{1.5+\mathrm{x} / 2^{3+}}\right]_{\mathrm{B}} \mathrm{O}_{4}{ }^{2-}
$$

In the present case $\mathrm{Cd}$ ions with large ionic radius $\left(0.97 \mathrm{~A}^{\mathrm{O}}\right)$ replace $\mathrm{Fe}^{3+}$ ions having ionic radius $0.69 \mathrm{~A}^{\mathrm{O}}$ on the tetrahedral site. Consequently, lattice parameter increases with increasing Cd content. Reddy et al reported slightly higher values of lattice parameter for the sample with $\mathrm{x}=0.2,0.4$, and 0.6.[10].

\section{Infrared absorption studies}

The Infrared absorption spectra of the samples in the range 200-800 ${ }^{\mathrm{cm}-1}$ were recorded at room temperature on PerkinElmer IR spectrometer (Model 783) in the KBr medium. IR spectra of the samples studied in the present case are shown in the Figure. The spectrum of pure Li-ferrite possesses four principal bands in the range

200-800 ${ }^{\mathrm{cm}-1}$ which are usually observed for mineral spinel [11,12]. Along with these four principle bands some shoulders have also been observed. The position of the principle bands along with the shoulders for these samples are shown in the Table 2. Table shows the values of the force constants Kt and Ko along with the bond length $\mathrm{R}_{\mathrm{A}}$ and $\mathrm{R}_{\mathrm{B}}$. The force constants $\mathrm{K}_{\mathrm{t}}$ and $\mathrm{K}_{\mathrm{o}}$ were calculated using Waldron's analysis [13].

The first principle band $\left(\mathrm{U}_{1}\right)$ for Li- ferrite is at about $810 \mathrm{~cm}^{-1}$ and it is found to shift towards $570 \mathrm{~cm}^{-1}$ as the $\mathrm{Cd}^{2+}$ content increases. The bandwidth of the absorption band also goes on increasing with the increase in $\mathrm{Cd}^{2+}$ content. In the mixed spinel ferrite, a tetrahedral site is occupied by both $\mathrm{Cd}^{2+}$ ions and $\mathrm{Fe}^{3+}$ ions with decreasing concentration of $\mathrm{Fe}^{3+}$ by 1 -x. This causes a charge imbalance at tetrahedral sites and probably makes oxygen ion shift towards the $\mathrm{Cd} 2+$ ions, which results in increase of force constant. Due to this reason the central frequency $\left(\mathrm{U}_{1}\right)$ shows decreasing trend from $610 \mathrm{~cm}^{-1}$ to $570 \mathrm{~cm}^{-1}$ with increase in Cd content in Li-ferrite. Waldron attributed the $\left(\mathrm{U}_{1}\right)$ band to the intrinsic vibrations of the tetrahedral group. Thus, it is clear that $\mathrm{Cd}^{2+}-\mathrm{O}^{2-}$ complex are responsible for the occurrence of the $\left(\mathrm{U}_{1}\right)$ band.

The $\left(\mathrm{U}_{2}\right)$ absorption band for Li ferrite is observed at $480 \mathrm{~cm}^{-1}$. As the Cd content increases $\mathrm{U}_{2}$ band shifts from $480 \mathrm{~cm}^{-1}$ to $430 \mathrm{~cm}^{-1}$ and its intensity also decreases. It is found to be minimum and reduce to mere shoulders for $\mathrm{x}=0.2$. For the remaining samples for which $x>0.2$ the $U_{2}$ band reappears with increasing bandwidth. The shifting of $U_{2}$ values from 480 
$\mathrm{cm}^{-1}$ to $430 \mathrm{~cm}^{-1}$ with increase in $\mathrm{x}$ is also due to charge imbalance at the octahedral site. Similar behaviour for $U_{1}$ and $U_{2}$ bands is reported by earlier investigators [14,15,16,17]. Decreasing intensity for the sample with $\mathrm{x}=0.1$ and 0.2 is due to migration of $\mathrm{Fe}^{2+}$ ion from tetrahedral site to octahedral site. Reappearance of $\mathrm{U}_{2}$ band for the samples with $\mathrm{x}>0.2$ is due to increasing concentration of $\mathrm{Fe}^{3+}$ ions on octahedral site. Hafner attributed $\mathrm{U}_{2}$ band due to presence of $\mathrm{Fe}^{3+}$ $\mathrm{O}^{2-}$ complexes at the octahedral site [18]. Potakova et al have reported displacement and decrease in intensity of $\mathrm{U}_{2}$ band in case of $\mathrm{Zn}^{2+}$ doped in highly ferrous nickel ferrites [19]. Reddy et al in case of pure Lithium and Li-Ni ferrite reported decrease in intensity and disappearance of $\mathrm{U}_{2}$ band [20].

$\mathrm{U}_{3}$ absorption band in present case is found for the samples up to $\mathrm{x}=0.4$. For the remaining samples $\mathrm{U}_{3}$ band is absent. For these samples the concentration of $\mathrm{Li}^{1+}$ goes on decreasing by $0.5-\mathrm{x} / 2$ on the octahedral site. Therefore, $\mathrm{U}_{3}$ band can be attributed to the $\mathrm{Li}^{1+}-$ $\mathrm{O}^{2-}$ metal complexes at the octahedral site.

Frequency of $U_{4}$ band depends on the mass of the tetrahedral cation and is assigned to vibrations of tetrahedral metal ion $[21,22]$. In the present case, the intensity of $U_{4}$ band is lowest among all the IR bands and is observed only for the samples up to the value of $x=0.3$. The reason for absence of $U_{4}$ band for the samples having $\mathrm{x}>0.3$ is that at the tetrahedral site the concentration of $\mathrm{Fe}^{3+}$ decreases by $1-x$. Thus, the vibrational band $U_{4}$ band may be attributed to the presence of $\mathrm{Fe}^{3+} \mathrm{O}^{2-}$ ions at the tetrahedral site.

Potakova et al have shown that existence of side band can be considered as evidence for the presence of $\mathrm{Fe}^{2+}$ ions [23]. Similar Splitting and disappearance of IR absorption bands has been reported by Reddy et al in case of Li-Ni and Li-Ti ferrites [24,25].

Scanning electron microscope of the samples were recorded at Regional sophisticated Instrumentation Centre Nagpur using Model Cambridge Stereoscan S-250 MKII. Figure 4 shows the SEM micrographs of the samples with $\mathrm{x}=0,0.1$. The data on composition and grain size is shown in Table 4. The variation of grain size with composition is shown in Figure 5. It is found that grain size increases with increase in $\mathrm{Cd}$ content up to $\mathrm{x}=0.1$. On further addition of $\mathrm{Cd}$ with $\mathrm{x}=0.3,0.5,0.7$ the grain size decreases.

Table 1 shows values of the lattice parameter (a) for different values of ' $x$ '.

\begin{tabular}{|c|c|c|}
\hline Sr. No. & $\mathrm{X}$ & Lattice parameter (a) $\mathrm{A}^{0}$ \\
\hline 1. & 0.0 & 8.324 \\
\hline 2. & 0.1 & 8.364 \\
\hline 3. & 0.2 & 8.4328 \\
\hline 4. & 0.3 & 8.4533 \\
\hline 5. & 0.4 & 8.5123 \\
\hline 6. & 0.5 & 8.5266 \\
\hline 7. & 0.6 & 8.6006 \\
\hline 8. & 0.7 & 8.644 \\
\hline
\end{tabular}


Table 2 Data on lattice vibration frequencies and side bands for $\mathrm{Li}_{0.5-\mathrm{x} / 2} \mathrm{Fe}_{2.5-\mathrm{x} / 2} \mathrm{Cd}_{\mathrm{x}} \mathrm{O}_{4}$ ferrites

\begin{tabular}{|l|l|l|l|l|l|l|l|l|}
\hline $\mathrm{X}$ & $\mathrm{U}_{1}$ & $\mathrm{U}_{1 \mathrm{~s}}$ & $\mathrm{U}_{2}$ & $\mathrm{U}_{2 \mathrm{~s}}$ & $\mathrm{U}_{3}$ & $\mathrm{U}_{3 \mathrm{~s}}$ & $\mathrm{U}_{4}$ & $\mathrm{U}_{4 \mathrm{~s}}$ \\
\hline 0.0 & 610 & 560 & 480 & 450 & 400 & 380 & 340 & 310 \\
\hline 0.1 & 605 & -- & 480 & -- & 400 & & 360 & 310 \\
\hline 0.2 & 600 & -- & 480 & 425 & 400 & 380 & 360 & 310 \\
\hline 0.3 & 590 & -- & 470 & 410 & 400 & -- & 360 & -- \\
\hline 0.4 & 590 & -- & 460 & 440 & 400 & -- & -- & -- \\
\hline 0.5 & 580 & -- & 440 & -- & -- & -- & -- & -- \\
\hline 0.6 & 570 & -- & 410 & -- & -- & -- & -- & -- \\
\hline 0.7 & 570 & -- & 400 & -- & -- & -- & -- & -- \\
\hline
\end{tabular}

Table 3 Bond lengths and force constants for $\mathrm{Li}_{0.5-\mathrm{x} / 2} \mathrm{Fe}_{2.5-\mathrm{x} / 2} \mathrm{Cd}_{\mathrm{x}} \mathrm{O}_{4}$ ferrites

\begin{tabular}{|c|c|c|c|c|}
\hline & & & \multicolumn{2}{|c|}{ Force Constants } \\
$\mathrm{x}$ & $\mathrm{R}_{\mathrm{A}} \mathrm{A}^{\mathrm{O}}$ & $\mathrm{R}_{\mathrm{B}} \mathrm{A}^{\mathrm{O}}$ & $\mathrm{K}_{\mathrm{t}} \times 10^{5}$ & $\mathrm{~K}_{\mathrm{O}} \times 10^{5}$ \\
\hline 0.0 & 2.005 & 2.084 & 1.38 & 2.76 \\
\hline 0.1 & 2.014 & 2.093 & 1.46 & 2.70 \\
\hline 0.2 & 2.030 & 2.110 & 1.52 & 2.64 \\
\hline 0.3 & 2.035 & 2.115 & 1.51 & 2.54 \\
\hline 0.4 & 2.049 & 2.130 & 1.49 & 2.53 \\
\hline 0.5 & 2.053 & 2.134 & 1.40 & 2.44 \\
\hline 0.6 & 2.071 & 2.152 & 1.24 & 2.35 \\
\hline 0.7 & 2.081 & 2.163 & 1.20 & 2.34 \\
\hline
\end{tabular}

Table 4 Composition and grain size of $\mathrm{Li}_{0.5-\mathrm{x} / 2} \mathrm{Fe}_{2.5-\mathrm{x} / 2} \mathrm{Cd}_{\mathrm{x}} \mathrm{O}_{4}$ ferrites

\begin{tabular}{|l|c|}
\hline $\mathrm{X}$ & Grains size $\left(\mu_{\mathrm{m}}\right)$ \\
\hline 0.0 & 0.98 \\
\hline 0.1 & 2.35 \\
\hline 0.3 & 1.50 \\
\hline 0.5 & 1.30 \\
\hline 0.7 & 0.97 \\
\hline
\end{tabular}




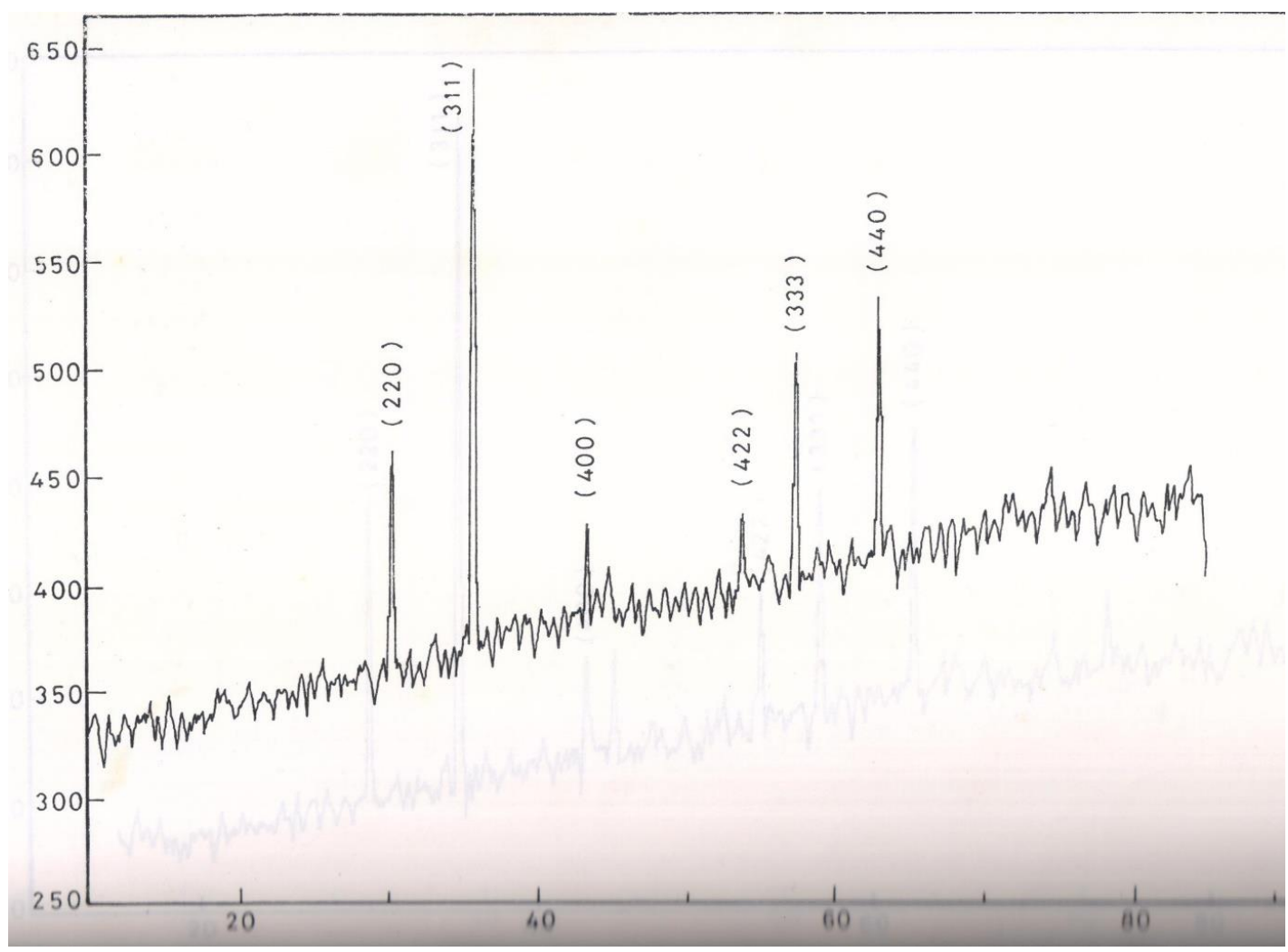

Figure 1. X-ray diffraction pattern of Li-Cd ferrite with $\mathrm{X}=0.1$

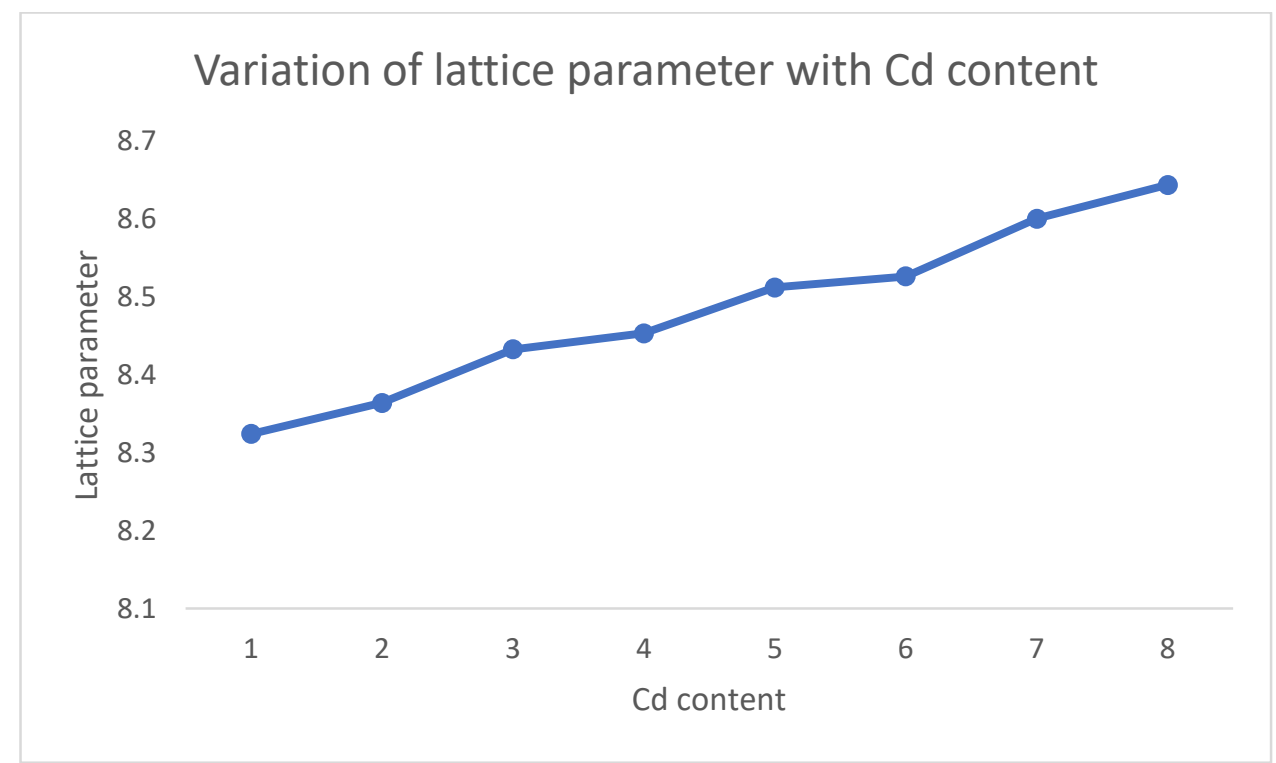

Figure 2 Variation of lattice parameter with $\mathrm{Cd}$ content 


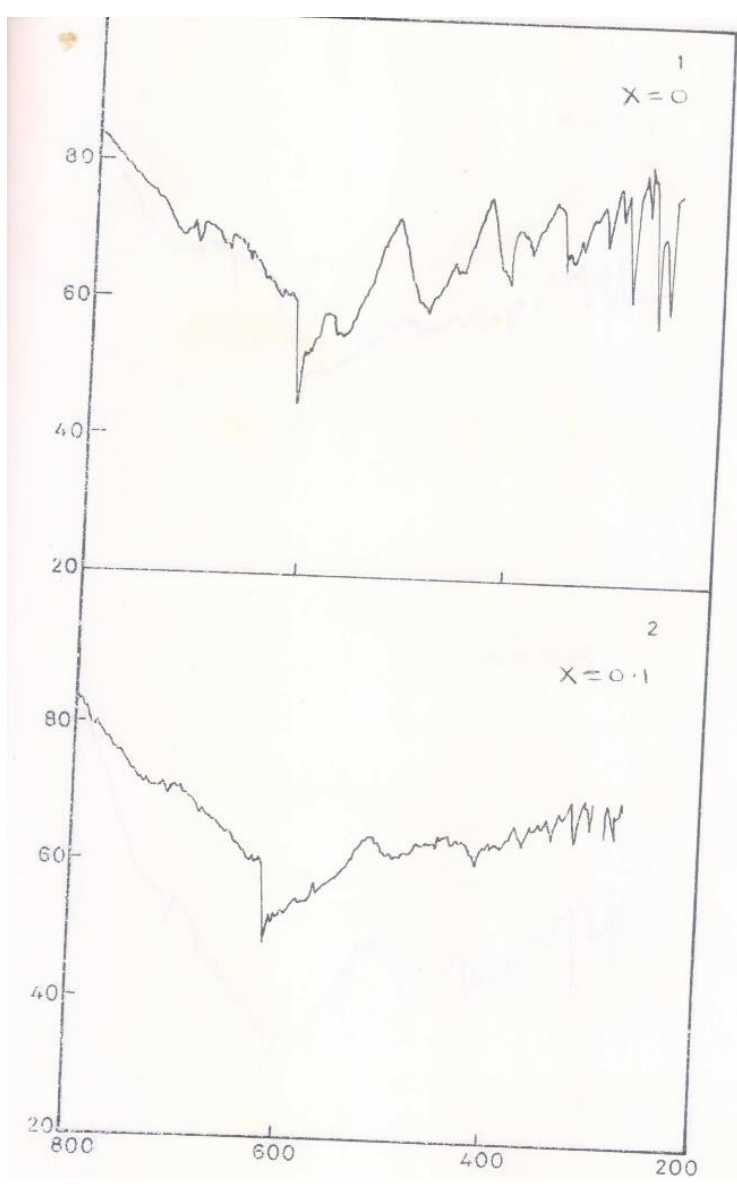

Figure 3. IR absorption spectra of $\mathrm{Li}$-Cd ferrites.

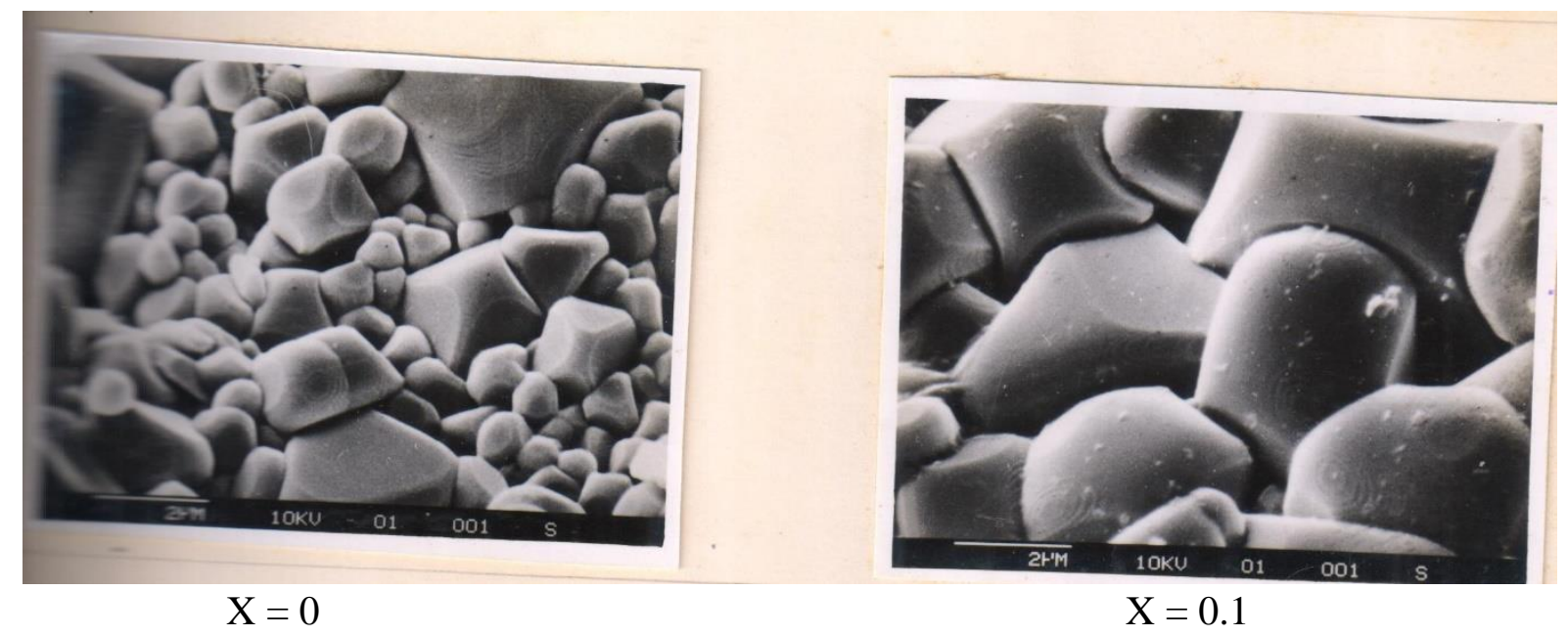

Figure 4. SEM of Li-Cd ferrite with $X=0$ and $X=0.1$ 


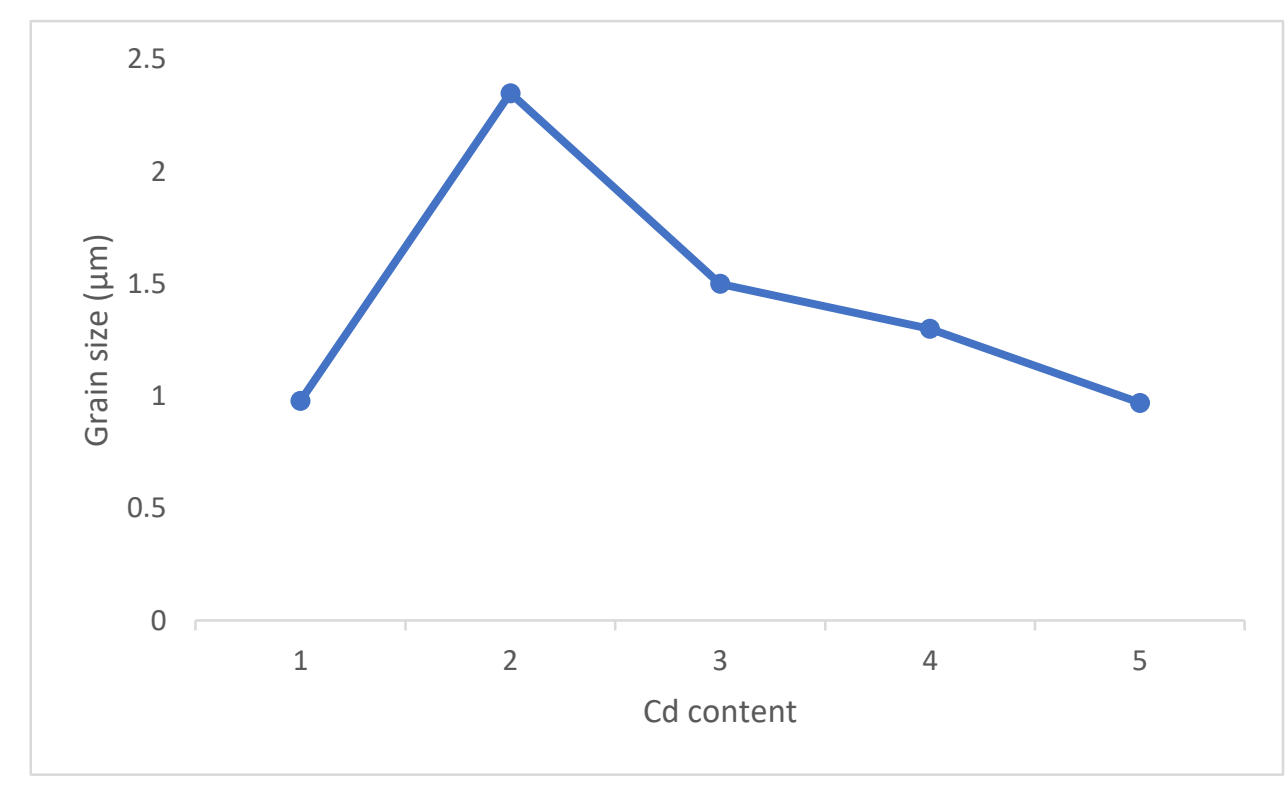

Figure 5 shows variation grain size with $\mathrm{Cd}$ content.

\section{References}

1. Sato T., Haneda K., Seki M., Iijima T., Morphology and magnetic properties of ultrafine $\mathrm{ZnFe}_{2} \mathrm{O}_{4}$ particles, Applied Physics A 1990, (50) 13

2. Uzma Ghazanfar S.A., Siddiqui G.A., "Structural analysis of the Mn-Zn ferrites using XRD technique"Materials Science Engineering B 118(2005) 84

3. Hoffman A., Crystal chemistry of Lithium ferrite, Naturewissenschaften 26(1938) 431

4. Wang F.E.Y., Gravel R.L., and Kestigen M. IEEE Transaction on Magnet., 4(1)(1968) 55

5. West R.G. and Blankenship A. C. "Magnetic Properties of Dense Lithium Ferrites"Journal of American Ceramic Society Vol. 50 No.7 (1967)

6. Baba P.D., Argentina C.N. and Courtney W.E. IEEE Trans. Trans on Magnetics, Mag-8 (1972) 83

7. Gorter E.W.

Philips Research Reports 9(1954)295

8. Naik A.B., Patil S.A. and Pawar J. I., "X-ray and magnetisation studies on Li-Cu mixed ferrites" Journal of Materials Science Letters 7(1988)1034

9. West R.G. and Blankenship A.C. Magnetic Properties of Dense Lithium Ferrites" Journal of American Ceramic Society, Vol.50, N0.7(1967)343

10. Reddy V.D. and Reddy P.V., "Elastic behaviour of lithium-cadmium mixed ferrites" Physica Status Solidi(a) 127(1991)349

11. Badrinath K.V.S. "The Far Infrared Spectra of MgAl2-x FexO4 Spinel"

Physica Status Solidi (a) K19(1985)91

12. Mitusuchi A., Yashinagae H. and Fugita X.

Journal of Physical Society17(1985)126

13. Waldron R.D.

Physics Review 99(1955)1727 
14. Josyulu O.S. and Sibhadri J.

Physica Status Solidi (a) 65(1981)479

15. Badrinath K.V.S.

Physica Status Solidi (a)K 19 (1985)91

16. Srinivasan T.T., Srivastav T.M. , Venkatramani N "Infrared absorption in spinel ferrites" Bulletin of Materials Science (India) 6, 1063 (1984)

17. Reddy P. V. and Shaligram M.

"The far-infrared spectra of mixed manganese-magnesium” Physica Status Solidi(a) 100(1987) 639

18. Hafner S.T.

Z. Fur. Krist. 115(1961)331

19. Potakova V.R., Zevery N.D. and Romanov V.R. "On the cation distribution in $\mathrm{Ni} 1-x-y \mathrm{Fe}-2 \mathrm{O} 4$ spinel ferrites" Physica status solidi (a) 12 (1972)623

20. Reddy P.V.and Reddy V.D.

Journal of Magnetism and Magnetic Materials 136. (1994)279

21. Josyulu O.S. and Sobhadri J.

"The far-infrared spectra of some mixed cobalt zinc and magnesium zinc ferrites"Physica status solidi (a) 65(1981)479

22. Preudhome J. and Tarte P.

Spectrochim acta 27A (1971) 961

23. Potakova V.R., Zevery N. D. and Romanova V.R.

Physica Status Solidi (a) 12 (1972) 623

24. Reddy P.V. and Reddy V.D.

"Far-infrared spectral studies of some lithium-nickel mixed ferrites", Journal of Magnetism and Magnetic Materials 136 (1994) 279

25. Reddy M.B., Reddy V.D., Mulay V.N, and Reddy P.V.

Materials Science Engineering B( In press) 